\title{
REGULAÇÃO DAS CRIPTOMOEDAS: POLÍTICA ANTI-LAVAGEM DE DINHEIRO
}

\section{CRYPTOCURRENCIE'S REGULATION: ANTI-MONEY LAUNDERING POLICY}

\author{
Hadassah Laís De Sousa Santana ${ }^{1}$ \\ Felipe Américo Moraes²
}

\section{RESUMO}

Trata de pesquisa realizada através de levantamento bibliográfico e legislação vigente, com o fim de identificar o modo como o Estado brasileiro têm buscado adequar-se frente às orientações internacionais para combate do crime de lavagem de dinheiro praticado através das criptomoedas. Para tanto, após contextualização sobre o universo das criptomoedas, será exposto como a comunidade internacional está se posicionando frente à necessidade de regulamentação dessa atividade, em especial do objetivo de evitar e mitigar os riscos da lavagem e dinheiro. Após, será realizada uma comparação entre as normas vigentes no brasil e as tendências regulatórias nacionais, através da observação dos projetos de lei que se encontra em tramitação. A conclusão é de que, em que pese no Brasil exista projeto de lei que atende fielmente às orientações internacionais para combate da lavagem de dinheiro através das criptomoedas, inexiste norma vigente que atenda, ainda que minimamente, qualquer um desses requisitos.

Palavras-chave: criptomoedas; lavagem de dinheiro; regulação.

\begin{abstract}
This research carried out through bibliographic survey and current legislation, in order to identify how the Brazilian State has sought to adapt to international guidelines to combat the crime of money laundering practiced through cryptocurrencies. To this end, after contextualizing the cryptocurrency universe, it will be exposed how the international community is positioning itself against the need to regulate this activity, especially the objective of avoiding and mitigating the risks of money laundering. Afterwards, a comparison will be made between the norms in force in Brazil and the national regulatory trends, through the observation of the project of law that are being processed. The conclusion is that, in spite of Brazil there is a project of law that faithfully meets the international guidelines for combating money laundering through cryptocurrencies, there is no current rule that meets, even if minimally, any of these requirements.
\end{abstract}

Keywords: Cryptocurencies; Money laudering, regulation.

\footnotetext{
${ }^{1}$ Professora na pós-graduação do Instituto Brasiliense de Direito Público - IDP. Advogada no escritório Franco Jr. Advogados Associados. Doutora em Educação pela Universidade Católica de Brasília - UCB. Mestre em Direito Tributário pela Universidade Católica de Brasília (2014). Possui especialização em direito Tributário e Finanças Públicas pela Escola de Administração Fazendária - ESAF (2011).

${ }^{2}$ Mestrando em Direito Econômico e Cidadania pelo Centro Universitário de Curitiba. Especialista em Direito Penal Econômico e Empresarial pela Universidade Positivo (2015). Graduado pela Pontifícia Universidade Católica do Paraná (2013). É advogado.
} 


\section{INTRODUÇÃO}

Preocupação com ativos eletrônicos não são recentes e originadas das, agora populares, criptomoedas. Ainda no ano de 1995 era possível aos norte-americanos realizarem a conversão de seus ativos em moedas eletrônicas, com objetivo de garantir maior anonimato às transações realizadas, fato que à época já sugeriu sensível preocupação com, dentre outras fraudes, a lavagem de dinheiro (RIBEIRO, 2017). Milton Friedman, ainda no ano de 1977, relatou as tendências de regulamentação global do mercado financeiro, seja por instituições públicas ou privadas, com objetivo de prevenir o fluxo transnacional de recursos ilícitos (CARVALHO, 2018).

Entretanto, tais movimentos, que à época se apresentavam menos significativos, ganharam especial relevância frente ao surgimento das criptomoedas. A primeira delas, o Bitcoin, criada no ano de 2008 como proposta como alternativa às moedas de emissão Estatal e teve sua popularidade alavancada pela crise norte-americana do subprime.

O tema passa a ser ainda mais relevante pelo fato de que, em 2018, foi identificado um mercado de 1.800 criptomoedas, com uma capitalização de mercado de mais de 300 bilhões de dólares. Desses, $26 \%$ dos usuários estão associados à atividade ilegais ${ }^{1}$. Há estimativa de que 45\% das transações em bitcoin, a principal criptomoeda, estejam associadas com transações ilegais, sendo apontado que 49\% de todo o mercado de bitcoin já passou por alguma operação ilícita. Esses usuários realizam aproximadamente 37 milhões de transações por anos, com um valor de totaliza 76 bilhões de dólares (FOLEY; KARLSEN; PUTNIN̦Š, 2019).

Diante disso, a possiblidade de regulação das criptomoedas passou a ser objeto de profunda discussão internacional. Foi, inclusive, tema da $2^{\text {a }}$ Sessão do Seminário de Tecnologia do G20, onde foram afirmadas preocupações sobre o modo como a regulação deverá advir. Há o desafio para balancear, de um lado, a promoção da inovação e, de outro, o dever de assegurar o interesse público em áreas como estabilidade financeira, proteção do consumidor e estabelecimento de políticas Anti-Lavagem de Dinheiro (adiante, ALD). Enquanto a regulação pode prevenir crimes, também pode mitigar a inovação, o que pode ocorrer através das tentativas de controlar todos os riscos imagináveis das novas tecnologias antes mesmo da percepção dos seus benefícios (ENDO, 2019).

\footnotetext{
${ }^{1}$ São 27.81 milhões de usuários envolvidos com atividades ilícitas, com uma contrapartida de 78.44 que atuam dentro da licitude.
} 
A tecnologia blockchain e o sistema de protocolos que podem ser implementados tem o potencial de revolucionar a indústria. Essa tecnologia, entretanto, tem encontrado resistência, especialmente dos órgãos reguladores. Devido à alta complexidade, aliado ao grande receio que se possui quanto aos eventuais riscos, é possível que a regulação acabe por impedir que as inovações ocorram devido à tentativa de se evitar todos os riscos possíveis da implementação da tecnologia (FOLEY; KARLSEN; PUTNIN̦S, 2019).

Evidentemente, os países que têm se dedicado a promover regulações para controle dos crimes de lavagem de dinheiro. Após o advento das criptomoedas o fato a atenção tem sido, pouco a pouco, também destinado a elas. O que fará a presente pesquisa é identificar as orientações e tendências internacionais da política ALD e, após, avaliar como as autoridades brasileiras que possuem capacidade reguladora têm se posicionado.

Para chegar às conclusões, será necessário, em um primeiro momento, realizar levantamento das tendências de regulamentação das criptomoedas em âmbito internacional para fins de atender à política ALD e, após, verificar se tais movimentos estão sendo acompanhados pelas regulamentações brasileiras. Mas antes, faz-se breves conceituações sobre o universo das criptomoedas.

\section{BREVES CONCEITUAÇÕES SOBRE CRIPTOMOEDAS}

A principal característica das criptomoedas é sua origem alheia à atuação e controle de uma autoridade central e, via de consequência, sem a necessidade de intermediários, tais como as instituições financeiras (NAKAMOTO, 2008). Afirma-se, portanto, que as transações são realizadas diretamente entre os sujeitos, também entendidos como transações de ponto a ponto ou, mais popularmente, peer-to-peer $(\mathrm{P} 2 \mathrm{P})$.

Para assegurar a confiabilidade das transações, todas são realizadas através de verificações via blockchain, sendo essa uma tecnologia baseada na distribuição de dados através de inúmeros computadores conectados à internet, sem qualquer controle por empresa ou autoridade central, e que pode ser acessada por qualquer usuário na rede. Qualquer pessoa que realize uma operação Peer-to-peer via blockchain possui a garantia de que há o armazenamento, de maneira criptografada, concomitantemente em todos os computadores da rede, dos dados da transação, garantindo, assim, a fidelidade da informação, sendo todas as informações inseridas em um grande "livro-razão" (IANSITI; LAKHANI, 2017). Nada mais é do que uma 
infraestrutura aberta e global que permite às empresas e os indivíduos realizarem transações sem intermediários, reduzindo, assim, os custos de transação (ULRICH, 2014). Além disso, é por meio do blockchain que é garantida a ausência de interferência de outras autoridades financeiras ou governamentais na emissão (mineração) das criptomoedas (ESTELLITA, 2019).

Os históricos das transações são sempre de conhecimento público. O blockchain, por ser acessível a qualquer usuário e por ser absolutamente irreversível, torna possível o conhecimento a qualquer pessoa sobre a movimentação financeira da criptomoeda que recebe, independente do fato de as transações anteriores terem sido realizadas de modo P2P. Entretanto, não é possível acessar as informações dos usuários que a realizaram. Fala-se, portanto, que as transações são pseudoanônimas.

Há sete categorias de agentes dentro do universo das criptomoedas: (1) usuários, que são as pessoas, físicas ou jurídicas, que utilizam a criptomoeda como meio de pagamento ou custódia de valor; (2) mineradores, que são os responsáveis pelo lançamento de novas criptomoedas no mercado, extraindo-as, através de operações computacionais; (3) exchanges, aqueles que realizam a conversão entre criptomoeda e moeda fiduciária, ou entre criptomoedas de diferentes naturezas; (4) plataformas de troca, que permitem a troca de criptomoedas diretamente entre os usuários; (5) provedores de carteira, que são softwares o hardwares que auxiliam o usuário na guarda de informações de suas criptomoedas, de maneira criptografada; (6) inventores de moedas, que são aqueles que, com o uso da tecnologia adequada, criam novas criptomoedas e definem as regras de utilização; e os (7) ofertantes de moedas, que são os responsáveis por fazer a distribuição das criptomoedas (HOUBEN; SNYERS, 2018).

Agentes de maior relevância para o tema são, além dos usuários, que poderão ser os sujeitos do crime de lavagem e dinheiro, as exchanges, as plataformas de troca e os provedores de carteiras, que se enquadram em um gênero recentemente definido como "virtual asset service providers" ou "VASPs", o qual será objeto de análise adiante.

\section{3 (IR)RELEVÂNCIA DA NATUREZA JURÍDICA DAS CRIPTOMOEDAS PARA ATENDIMENTO DA POLÍTICA ANTI-LAVAGEM DE DINHEIRO}

Inexiste, atualmente, consenso quanto à natureza jurídica das criptomoedas. As definições circundam classificações como (i) moeda virtual; (ii) moeda digital; (iii) contrato; (iv) ativo financeiro; (v) commodity; (vi) título de crédito virtual; (vi) valor mobiliário; (vii) 
criptoativo, dentre outras menos populares. Entretanto, a tendência é que a natureza jurídica seja determinada por imposição legal. Há em trâmite o Projeto de Lei no 2303/2015 (RIBEIRO, 2015), o qual pretende enquadrar a criptomoeda como "moeda virtual" (DALCASTER, 2018).

Embora as recorrentes discussões no meio acadêmico sobre se as criptomoedas serem, ou não, moeda, entende Malcom Campbell-Verduyn (2018) que a discussão, para o ponto de vista de uma governança global ALD, é pouco relevante. Segundo ele, pouco importa a classificação teórica desses bens, mas, sim, sua participação em transações ilícitas e fluxos financeiros regulado e, dentro desse universo, especialmente, das exchanges e suas operações cambiais entre moedas fiat e criptomoedas. Assim, o presente artigo, embora por fidelidade teórica afirme a celeuma existente quanto ao tema, não abordará questões relativas à natureza jurídica das criptomoedas.

Entretanto, concorda-se que a conceituação como "moeda vitual" está aquém da correta natureza jurídica das criptomoedas; ao menos para o modo como tem sido utilizada. Devido à elevada volatilidade, sua função tem apresentado muito mais proximidade com um ativo financeiro do que, de fato, uma moeda utilizada para intermediar transações, sendo estranho que a definição da natureza jurídica como "moeda" seja dada por imposição legal, enquanto seu uso, ao menos atualmente, não se comporta como tal.

A relevância temática, portanto, é somente quanto à finalidade do órgão regulador que poderá exercer a regulação. Se classificada como moeda, será pelo Banco Central; se como ativo financeiro, pela Comissão de Valores Mobiliários - CVM (DALCASTER, 2018).

\section{POLÍTICA ANTI-LAVAGEM DE DINHEIRO}

Quando se trata de identificar condutas de lavagem de dinheiro, há dois elementos fundamentais e estruturais dessas tecnologias que dificultam o funcionamento dos tradicionais mecanismos de combate: a descentralização e o pseudoanonimato (RODRIGUES et al., 2019).

Assim, as tendências regulatórias ALD, baseadas no fato de que é possível conhecer todo o caminho percorrido por aquele "ativo virtual", mas não o indivíduo que o realizou, têm sido direcionados às entidades privadas que realizem ou auxiliem os usuários nessas transações. Há três tendências regulatórias principais: (i) autorregulação industrial; (iii) a abordagem baseada em risco do Financial Action Task Force (adiante FATF); e as (iii) iniciativas nacionais (CAMPBELL-VERDUYN, 2018). 


\subsection{Autorregulação Industrial}

Autorregulação Industrial se relaciona às medidas adotadas voluntariamente por atores desse ecossistema de criptomoedas para a observância de normas ALD. exchanges, que fazem operações de câmbio entre criptomoedas e moedas fiat, não raramente impõem certas exigências a seus clientes, como o fornecimento de comprovantes de residência e documentos de identificação, inobstante inexista um consenso de quais medidas devam ser tomadas (RODRIGUES et al., 2019).

Iniciativas dessa mesma natureza incluem orientações emitidas pela Digital Asset Transfer Authority (DATA), uma autorreguladora que, no ano de 2015, submeteu proposta de diretrizes, afirmando que, sendo exigidos ou não por lei de cada país, todas as companhias de "ativos digitais" devem possuir um Chief Compliance Officer, devem (i) realizar treinamento dos empregados sobre política ALD para identificação de transações suspeitas, (ii) realizar processos de due diligence das partes envolvidas nas transações, (iii) limitar de transações e contas, (iv) realizar determinados procedimentos quando houver identificação de transações suspeitas, incluindo orientações claras a quem se deverá reportar, bem como (v) realizar a manutenção de dados das transações e possibilidade de fácil compartilhamento caso necessário.

Movimento semelhante foi inaugurado no Reino Unido no ano de 2018, pela nominada CryptoUK, associação representativa da indústria que elaborou um código de conduta para autorregulação (CRYPTOUK, 2018). Em outubro do mesmo ano, instituição fundada por 16 exchanges operantes no Japão recebeu amplos poderes regulatórios da autoridade financeira do país, inclusive o de supervisionar, normatizar, sancionar, receber reclamações e oferecer consultoria para exchanges (URANAKA, 2018).

\subsection{Abordagem baseada em risco do Financial Action Task Force - FATF}

O Financial Action Task Force - FATF é uma entidade intergovernamental, estabelecida no ano de 1989, por iniciativa à época dos países-membros da OCDE. Um de seus objetivos é compilar, de tempos em tempos, os pilares para a organização internacional de combate à lavagem de dinheiro e financiamento do terrorismo, sendo, agora, endossado por mais de 180 países e universalmente reconhecido como um organizador dos pilares internacionais da política ALD (HOUBEN; SNYERS, 2018). 
Especificamente sobre o tema das criptomoedas, o FATF (2019) elaborou recomendações para que os países adotem. É, portanto, adequado utilizá-la como base para narrar as tendências internacionais sobre, principalmente, a regulação em matéria de lavagem de dinheiro.

Vale destacar que essa entidade afirma a insuficiência da autorregulação para fins de política ALD. Há recomendação para que os Estados designem autoridades competentes para supervisão desses provedores de serviços, não bastando que estejam sujeitos à mera autorregulação industrial. Há expressa recomendação de que haja a supervisão das entidades que realizem operações com criptomoedas, por autoridades competentes, os quais devem, com a força adequada para conduzir investigações e impor sanções, monitorar as transações. As recomendações afirmam a necessidade de identificar riscos e tomar medidas para efetivamente mitiga-los, colocando mecanismos, tais como grupos de trabalho ou forças-tarefa, para fomentar legisladores e/ou reguladores em buscar adequar à essa política ALD.

E o método como isso pode ser realizado é através da imposição de normas, igualmente estipuladas pelo FATF, para especificamente os agentes mais sensíveis desse universo das criptomoedas. Até o ano de 2018, falava-se em destinar atenção às exchanges, eis que são o ponto de contato entre a moeda fiduciária e a criptomoeda, mas, tendo em vista o crescente desenvolvimento de novas tecnologias que não se enquadravam nessa categoria, mas, ainda sim, oferecem serviços que contribuem para o anonimato, foi inaugurado no ano de 2019 um novo gênero: os Virtual Asset Service Providers, ou somente VASPs, que engloba todos os sistemas que realizam operações com criptomoedas e seus usuários, estando nele inclusos, além das exchanges, as plataformas de troca e os provedores de carteiras.

Conceitua-se VASPs como toda pessoa natural ou legal que realize câmbio entre "ativos virtuais" e moeda fiat, câmbio entre um ou mais formas de "ativos virtuais", transferência de "ativos vituais", guarda e/ou administração dos "ativos virtuais" ou que permitam seu controle (tais como as carteiras/wallets).

As recomendações do FATF, agora, são destinadas à essa nova categoria, sendo recomendado às autoridades nacionais a nível mundial desenvolvam um ambiente regulatório sobre os VASPs, devendo ser supervisionados, obrigados a licenciar-se ou registrar-se perante uma autoridade nacional (FATF, 2019). Além disso, há recomendação para que atenção extravase também pra outros agentes sensíveis, tais como profissões ou entidades, ainda que não financeiras, mas mais suscetíveis à prática desse crime. ${ }^{2}$

\footnotetext{
${ }^{2} \mathrm{O}$ guia utiliza o termo "Designated Non-Financial Business and Professions" (DNFBP).
} 
Outra alteração que merece atenção é o fato de que o FATF introduziu termo que possui objetivo de unificar a nomenclatura utilizada para criptomoedas: ativos virtuais (virtual asset, ou somente VA).

As recomendações do FATF para atendimento da política ALD envolve: (i) possibilidade de confisco pelo Estado; (ii) necessidade de registro ou licenciamento dos VASPs; (iii) exercício de supervisão e monitoramento das transações por autoridade externa; (iv) criação de métodos preventivos ALD; (v) fomentar a transparência das transações, incluindo o dever de informar transações suspeitas e guardar registros; (vi) criação de Leis para regulamentar a matéria; e (vii) cooperação com autoridades nacionais e internacionais. Fala-se brevemente sobre cada uma delas. Fala-se sobre elas.

Quando fala sobre a possibilidade de confisco pelo Estado, o FATF afirma que os ativos virtuais são um tipo de propriedade com valor intrínseco, sendo possível, portanto, identificalos eventualmente como produto de crime, para que possa haver adequação à atual legislação que permita o confisco, ou imediato bloqueio, independentemente de como aquela jurisdição classifique juridicamente as criptomoedas. Reafirma-se, portanto, a pouca relevância da discussão da natureza jurídica das criptomoedas para fins de lavagem de dinheiro.

Recomenda que os países designem uma ou mais autoridade para que ser responsável pelo licenciamento ou registro dos VASPs, os quais deverão requerer tais habilitações dentro das jurisdições que foram criadas. Essas autoridades deverão impor condições para permitir adequada supervisão, bem como tomar medidas ou criar mecanismos para identificar a pessoa, física ou jurídica, que atue como VASPs sem o devido registro ou licença, aplicando-as sanções.

Mais verticalmente, recomenda que os países desenvolvam um efetivo sistema de controle, supervisão e monitoramento dos VASPs, para fins ALD, devendo a atividade ser realizada por uma autoridade competente, e não através de autorregulação. Quanto às instituições financeiras e algumas profissões ou entidades, ainda que não financeiras, mas suscetíveis à prática desse crime, tais como casas de jogos, agentes de investimentos, negociadores de metais e pedras preciosas, advogados e outros profissionais liberais, há recomendação para que haja maior supervisão das atividades financeiras, devendo estar sujeitas a mais incisiva regulação.

Outra medida é o dever de aplicar métodos preventivos, designando procedimentos de Due Diligence para que os VASPs, enquanto entidade obrigada, identifique as pessoas envolvidas na transação e, quando aplicável, o beneficiário, além de verificar dentro do escopo de uma análise de risco, informações, dados ou documentos, para compreender os motivos e a 
natureza do negócio pactuado entre as partes, e verificar informações que possam sugerir o alto risco de eventual transação para fins ALD. Também, recomenda o dever de coleta de informações relevantes em transações que ultrapassem USD/EUR 1.000, devendo diligenciar, também, em transações que envolvam “ativos virtuais” através de serviços, transações ou canais de entrega pseudoanônimas, tais como transações anônimas, para identificar o endereço de IP e os números dos documentos dos envolvidos.

Os países devem obrigar aos VASPs, e outras entidades, a manutenção de documentos, dados ou informações das transações de alto risco, além da guarda dos dados de todas as transações, independentemente de quais sejam, pelo prazo de cinco anos. Deve haver identificação dos envolvidos, chaves públicas, endereço ou contas envolvidas, natureza e data da transação, e o montante transferido. Afirma-se, ainda, que as informações gravadas em blockchain são insuficientes para adequação dessa recomendação, eis que não auxiliam autoridades a conectar a transação com o indivíduo que a realizou.

Países devem garantir que os VASPs licenciados ou em operação em sua jurisdição tomem medidas para mitigar os riscos de atividades que envolvam uso de tecnologias que fomentam anonimidade, principalmente os "anonymity enhancing cryptocurencies - AECs", "mixers"4, dentre outras, que ofuscam a identidade dos envolvidos em transações com "ativos virtuais".

Nesse ponto, afirma o dever de transparência, recomendando a imposição de que as entidades supervisionadas enviem informações relevantes assim que requisitadas, sendo que, de maneira ampla, todas as entidades que suspeitarem seriamente que os valores procedem de um crime devem reportar tais suspeitas para a autoridade competente. Como consequência, os países devem desestimular o uso ilícito dos VASPs, permitindo maior transparência e acesso às informações.

Por fim, recomenda ser dever dos países promoverem medidas, através da edição de leis e normas regulamentadoras, para conseguir as informações necessárias à política ALD, especialmente garantir o poder de obtenção compulsório desses registros. Do mesmo modo, devido ao caráter transnacional das criptomoedas, recomenda que uma regulação efetiva, supervisionada e suficientemente forte, a abordagem regulatória aos VASPs deve se dar a nível

\footnotetext{
${ }^{3}$ Criptomoeda que possui mecanismos e ferramentas que auxiliam aqueles que transacionem com ela a garantir maior anonimato.

${ }^{4}$ Serviço que, mediante pagamento de taxa, permite que os usuários realizem a troca de criptomoedas por outras, da mesma natureza ou não, dificultando ou impossibilitando a identificação do rastro da transação no blockchain. Comparativamente, é como se o usuário enviasse dinheiro para uma conta bancária (provedor do mixer), e houvesse a devolução da mesma quantia, por outra ou dezenas de outras pessoas, para a conta do usuário.
} 
global. Países devem desenvolver ferramentas para cooperar uns com os outros, identificar e bloquear ou confiscar os bens produtos de crime, sendo eles "ativos virtuais" ou os "ativos tradicionais" e ainda, providenciar a extradição dos sujeitos envolvidos nos delitos.

\section{TENDÊNCIAS INTERNACIONAIS SOBRE A REGULAÇÃO ANTI-LAVAGEM DE DINHEIRO}

Há três opções para regulação das criptomoedas: (i) através do poder legislativo; (ii) instrumentos normativos por agências reguladoras; e (iii) recomendações. Regulação por agências reguladoras possuem aplicação mais rápida, entretanto menor força normativa. Por seu turno, a regulação através da legislação, que institucionalmente são menos questionáveis, supriria a necessidade da força normativa, em que pese possa estar sujeita a pressões políticas (RODRIGUES et al., 2019).

Pesquisa destinada à identificar dentre os países membros do G20 sua atenção à política ALD, foi constatado que uma das importantes qualidades da boa regulamentação é a correta conceituação das criptomoedas. Segundo recomendação do FATF, deve possuir oito elementos: (i) representação digital de valor; (ii) transferível/comercializável; (iii) possibilidade de uso como meio de pagamento; (iv) armazenagem de valor; (v) unidade contábil; (vi) sem valor legal; (vii) uso de tecnologia descentralizada; (viii) não governamental (RODRIGUES et al., 2019). Atualmente, inexiste consenso entre os países do G20 sobre quais são os elementos conceituais das criptomoedas, podendo haver lacunas para aplicação da norma, incertezas quanto aos sujeitos regulados ou discricionariedade na fiscalização. Nenhum dos países apresentam conceitos que incluam todas essas características, o que pode revelar um desconhecimento por parte legisladores.

O mesmo problema é identificado na conceituação das exchanges. Os elementos conceituais são (i) câmbio entre criptomoeda e moeda fiduciária; (ii) câmbio entre diferentes moedas virtuais; (iii) emissão e controle de circulação de moeda virtual; (iv) compra e venda de ativos virtuais; (v) gerenciamento de ativos virtuais em nome de terceiros; (vi) facilitador de transações envolvendo ativos virtuais; (vii) provedor de serviços (RODRIGUES et al., 2019).

A definição de exchange é relevante, eis que, se ausente, poderá haver vácuo regulatório para esse empreendimento, ou o risco da confusão entre outros serviços. A importância decorre, justamente, do fato de que elas são o ponto de contato entre o sistema já altamente regulado das 
instituições financeiras e a liberalidade das criptomoedas, além de permitir uma regulação adequada para cada serviço (RODRIGUES et al., 2019). Importante destacar que, e que pese algumas das funções exercidas pelas exchanges se assemelhem às casas de câmbio, para não haver restrição à aplicação à determinados prestadores de serviços que podem, eventualmente, não possuírem tecnologia para fazer a conversão de uma moeda ou outra, mas serem, ainda assim, caracterizadas como exchanges e, via de consequência, devem estar em atendimento com as determinações da política ALD.

Sobre o atendimento da política ALD, foi identificado que dentre os membros do G20, 13 possuem atualmente regras e obrigações para identificação do usuário e cooperação com autoridades $^{5}$, 12 afirmam deveres de notificar transações suspeitas ${ }^{6}$ e preveem supervisão de autoridade externa ${ }^{7}, 11$ possuem deveres de guarda de registros ${ }^{8}, 10$ afirmam a existência de tempo mínimo para guarda de registros ${ }^{9}, 9$ afirmam a necessidade de registro perante uma autoridade ${ }^{10}$ e, por fim, 7 impõe limite de valor para indicar operações de alto risco ${ }^{11}$.

\section{REGULAMENTAÇÃO NO BRASIL}

No Brasil inexiste, até o momento de redação deste artigo, regulação que atenda aos padrões internacionais da política ALD. Há em vigência somente uma norma de caráter regulador e não legislativo: a Instrução Normativa 1.888/19, da Receita Federal, a qual institui e disciplina a obrigatoriedade de prestação de informações relativas às operações realizadas com criptoativos à Secretaria Especial da Receita Federal do Brasil.

\footnotetext{
${ }^{5}$ Sendo eles, União Europeia, Itália, Alemanha, Canadá, Japão, Austrália, México, França, Argentina, Rússia, Estados Unidos, Coreia do Sul, e Indonésia.

${ }^{6}$ União Europeia, Itália, Alemanha, Canadá, Japão, Austrália, México, França, Argentina, Rússia, Estados Unidos e Coreia do Sul.

${ }^{7}$ União Europeia, Itália, Alemanha, Canadá, Japão, Austrália, México, França, Argentina, Estados Unidos, Coreia do Sul, e Indonésia.

${ }^{8}$ União Europeia, Itália, Alemanha, Canadá, Japão, Austrália, México, França, Argentina, Rússia e Estados Unidos.

${ }^{9}$ União Europeia, Itália, Alemanha, Canadá, Japão, Austrália, México, França, Argentina e Estados Unidos.

${ }^{10}$ União Europeia, Itália, Alemanha, Canadá, Japão, Austrália, México, França e Indonésia.

${ }^{11}$ União Europeia, Itália, Alemanha, Canadá, Japão, Estados Unidos e Coreia do Sul.
} 
Quando comparados aos outros membros do G20, em que pese possuir uma das mais completas conceituações sobre criptoativos ${ }^{12}$ e exchange $e^{13}$, suas determinações possuem objetivo principal de garantir aplicação das normas tributárias, fato evidenciado através do exposto no "capítulo III" da referida Instrução, intitulada "Da Obrigatoriedade de Prestação de Informações", a qual impõe à exchange a obrigação de prestação de informações "para fins tributários no Brasil" (RECEITA FEDERAL, 2019) ${ }^{14}$. Afirma, com isso, a obrigatoriedade de as pessoas físicas ou jurídicas informarem transações quando forem superiores à $\mathrm{R} \$ 30.000,00$, o que revela somente a finalidade de realizar o controle tributário sobre valores relevantes, mas que estão em desacordo com a política internacional. Relembrando, o FATF recomenda que as exchanges sejam sujeitas às obrigatoriedades de informação das transações suspeitas em patamar muito menor, de mil dólares ou euros, com a finalidade de evitar, justamente, a prática de smurfing ${ }^{15}$.

Em que pese atualmente inexista em vigência norma ou lei que atenda às orientações internacionais ALD no Brasil, as tendências regulatórias marcham para um rumo adequado. Há ainda em fase inicial de tramitação o Projeto de Lei $n^{o} 3.825 / 19^{16}$, o qual sugere inclusões legislativas que melhor se adequam à política internacional ALD. Fala-se sobre todos.

Há a necessidade de autorização e registro das exchanges, impondo-lhes requisitos de documentação mínima, além de indicar o Banco Central como autoridade competente. Confirase:

“Art. 9, IV, do Projeto de Lei no 3.825/19: implantar mecanismos de diligências devidas para conhecimento e comprovação da identidade do cliente e de sua capacidade econômico-financeira".

“Art. $5^{\circ}$ do Projeto de Lei n ${ }^{\circ} 3.825 / 19$ : O processo de autorização para funcionamento da Exchange de criptoativos deve ser instruído com a apresentação de requerimento, mediante protocolo, ao Banco Central do Brasil, acompanhado de, no mínimo: I -

\footnotetext{
${ }^{12}$ Define-se criptoativo como "a representação digital de valor denominada em sua própria unidade de conta, cujo preço pode ser expresso em moeda soberana local ou estrangeira, transacionado eletronicamente com a utilização de criptografia e de tecnologias de registros distribuídos, que pode ser utilizado como forma de investimento, instrumento de transferência de valores ou acesso a serviços, e que não constitui moeda de curso legal", nos termos do art. $5^{\circ}$, I, da Instrução Normativa ${ }^{\circ} 1.888 / 19$.

${ }^{13}$ Define-se Exchange como "a pessoa jurídica, ainda que não financeira, que oferece serviços referentes a operações realizadas com criptoativos, inclusive intermediação, negociação ou custódia, e que pode aceitar quaisquer meios de pagamento, inclusive outros criptoativos", nos termos do art. $5^{\circ}$, II, da Instrução Normativa n ${ }^{\circ}$ $1.888 / 19$.

${ }^{14}$ Art. $6^{\circ}$, item I, da Instrução Normativa $n^{\circ} 1.888 / 19$.

15 Técnica de Lavagem de Dinheiro em que o sujeito realiza diversas pequenas transferências bancárias ou depósitos, com objetivo de não levantar suspeitas dos agentes financeiros acerca do montante total.

${ }^{16}$ De autoria do Senador Flávio Arns.
} 
justificativa fundamentada; II - documentação que identifique as pessoas que compõem o grupo econômico de que seja integrante a empresa e que possam vir a exercer influência direta ou indireta nos seus negócios; III - documentação que identifique o grupo de controle da empresa e os detentores de participação qualificada, com as respectivas participações societárias; IV - comprovação da origem e da respectiva movimentação financeira dos recursos utilizados no empreendimento pelos controladores e pelos detentores de participação qualificada; e V - declaração, firmada pelos participantes do grupo de controle e pelos detentores de participação qualificada, relativa à inexistência de restrições que possam, a juízo do Banco Central do Brasil, afetar sua reputação, acompanhada das fichas de antecedentes criminais. $\S$ $1^{\circ}$ A justificativa fundamentada mencionada no inciso I do caput deve contemplar, no mínimo: I - capital social; II - indicação pormenorizada dos serviços prestados; III público-alvo; IV - local da sede e eventuais dependências; V - sistemas e recursos tecnológicos; VI - estrutura de governança e plano de gerenciamento de riscos. $\S 2^{\circ}$ O Banco Central do Brasil poderá indicar, em regulamento, outros requisitos e documentos que julgar necessários. $\$ 3^{\circ}$ Qualquer alteração do modelo de negócio, como novo produto ou serviço, requer obtenção de licença junto ao Banco Central do Brasil.

\section{É prevista a necessidade de implantação de procedimentos de due diligence para} identificação das partes que realizarem as transações.

Art. 9, IV, do Projeto de Lei n ${ }^{\circ}$ 3.825/19: “implantar mecanismos de diligências devidas para conhecimento e comprovação da identidade do cliente e de sua capacidade econômico-financeira".

Inaugura o dever de prestação e compartilhamento de informações.

Art. 12. do Projeto de Lei $\mathrm{n}^{\circ}$ 3.825/19: As Exchanges de criptoativos devem prestar informações à Secretaria da Receita Federal do Brasil, nos termos por ela definidos.

Art. 14, Pará do Projeto de Lei $n^{\circ}$ 3.825/19grafo único, da Lei $n^{\circ} 3.825 / 19$ : "Informações sensíveis, como dados pessoais dos clientes, devem ser disponibilizados pela Exchange de criptoativos ao regulador em caso de requisição, considerando-se a negativa de atendimento como embaraço à fiscalização, sujeitando-a às sanções referidas no caput".

Afirma deveres de fiscalização por órgãos externos.

Art. 13 do Projeto de Lei $\mathrm{n}^{\mathrm{o}}$ 3.825/19. Compete ao Banco Central do Brasil: (...) II editar normas complementares para as Exchanges de criptoativos, inclusive sobre o objeto social, a constituição, o funcionamento e a fiscalização; (...) V - exercer vigilância sobre as operações com criptoativos; VI - supervisionar as Exchanges de criptoativos e aplicar as sanções administrativas cabíveis, com base na Lei ${ }^{\circ}$ 13.506, de 13 de novembro de 2017; 
Por fim, recomenda a adoção de medidas contra lavagem de dinheiro, sendo que o descumprimento poderá resultar (vi) em penalidades, (vii) medidas coercitivas ou outros meios já legalmente autorizados ao Banco Central.

\footnotetext{
"Art. $9^{\circ}, \mathrm{V}$, do Projeto de Lei $\mathrm{n}^{\circ}$ 3.825/19: "estabelecer medidas adequadas contra lavagem de dinheiro e demais crimes financeiros".

"Art. 11 do Projeto de Lei no 3.825/19: As Exchanges de criptoativos ficam sujeitas às infrações, penalidades, medidas coercitivas e meios alternativos de solução de controvérsias aplicáveis pelo Banco Central do Brasil, nos termos da Lei ${ }^{\circ}{ }^{0} 13.506$, de 13 de novembro de 2017".

“Art. 14 do Projeto de Lei no 3.825/19. No exercício das atividades de fiscalização, o Banco Central do Brasil poderá exigir da Exchange de criptoativos a exibição de documentos e livros de escrituração e o acesso, inclusive em tempo real, aos dados armazenados em sistemas eletrônicos, considerando-se a negativa de atendimento como embaraço à fiscalização, sujeitando-a às sanções aplicáveis na forma da Lei ${ }^{\circ}$ 13.506 , de 13 de novembro de 2017".
}

Observa-se, portanto, que tais leis, quando vigentes, se adequarão à todas as orientações internacionais do FATF quanto ao combate da lavagem de dinheiro.

Por fidelidade teórica, afirma-se que há o Projeto de Lei n 2303/2015, que trata sobre criptomoedas, mas é incapaz de dar respostas efetivas ao mercado, eis que não está acompanhando a necessidade de regulação devida às criptomoedas, como tem sido realizada em outros países (DALCASTER, 2018). Assim, não foi objeto do presente artigo por não contribuir minimamente com a política ALD.

\section{CONCLUSÃO}

Em que pese as tendências regulatórias brasileiras estejam de acordo com as orientações internacionais que visam combater o crime de lavagem de dinheiro praticado através das criptomoedas, inexiste norma vigente que atenda minimamente tal requisito.

Entretanto, o Projeto de Lei $n^{\circ} 3.825 / 2019$ preenche fielmente às orientações do FATF quanto às orientações internacionais da política ALD. Em que pese isso, não há lei atualmente em vigência. Esta última, que melhor atende às necessidades, encontra-se em fase prematura de tramitação.

Como dito, em que pese as normas sancionadas através do legislativo possuam maior força normativa, eis que são mais dificilmente questionadas, é fato que há maior lentidão para 
entrarem em vigência. Enquanto isso, autoridades que poderiam mais celeremente se dedicar à solução do problema passam longe de dirigir qualquer medida para mitigar os riscos advindos dessa nova tecnologia. Enquanto a Receita Federal Brasileira editou norma que visa exclusivamente a sonegação fiscal em transações que envolvam criptomoedas, a CVM, afirmada no presente artigo como um outro possível agente regulador, afirmou tão somente que será iniciado um sandbox regulatório sobre o tema (CVM, 2019), mas sem agir.

Outro ponto que merece destaque é que, em que pese as tendências regulatórias internacionais afirmem a criptomoeda como "ativo virtual", todas as autoridades brasileiras tem insistido na categorização como moeda. É fato que as criptomoedas foram criadas com objetivo de serem moedas, mas não se comportam como tal. Esse descompasso, entretanto, é relevante somente sob o ponto de vista de qual agencia reguladora teria capacidade de regular (se seria o Banco Central ou a CVM). Pouca importância teria para o atendimento à política $\mathrm{ALD}$, eis que, conforme exposto no decorrer deste. Bastaria verificar que as criptomoedas possuem valor intrínseco e, portanto, devem ser compreendidas eventualmente como proveito de crime.

Se conclui, portanto, que o brasil está em rumo de aderir às orientações internacionais para combate do crime de lavagem de dinheiro praticado através das criptomoedas, mas demorará a aderir completamente às medidas. Enquanto isso, o brasil passará longe de mitigar os riscos dessa expressiva atividade criminosa.

\section{REFERÊNCIAS}

ARNS, Flávio. Projeto de Lei no 3.825, de 2019. Disciplina os serviços referentes a operações realizadas com criptoativos em plataformas eletrônicas de negociação. Senado Federal, 2019.

Disponível em: https://www25.senado.leg.br/web/atividade/materias/-/materia/137512. Acesso em: 29 jan. 2020.

BRASIL. Instrução Normativa RFB no 1.888, de 03 de maio de 2019. Institui e disciplina a obrigatoriedade de prestação de informações relativas às operações realizadas com criptoativos à Secretaria Especial da Receita Federal do Brasil (RFB). Receita Federal, 2019. Disponível em:

http://normas.receita.fazenda.gov.br/sijut2consulta/link.action?visao=anotado\&idAto=100592 . Acesso em: 29 jan. 2020. 
BRASIL. Lei $\mathrm{n}^{\circ}$ 13.506, de 13 de novembro de 2017. Dispõe sobre o processo administrativo sancionador na esfera de atuação do Banco Central do Brasil e da Comissão de Valores Mobiliários. Disponível em: https://www2.camara.leg.br/legin/fed/lei/2017/lei-13506-13novembro-2017-785749-publicacaooriginal-154241-pl.html. Acesso em: 13 fev. 2020.

CAMPBELL-VERDUYN, Malcolm. Bitcoin, crypto-coins, and global anti-money laundering governance. Crime, Law and Social Change, v. 69, n. 2, p. 283-305, 2018. Disponível em: CAMPBELL-VERDUYN, Malcolm. Bitcoin, crypto-coins, and global anti-money laundering governance. Crime, Law and Social Change, v. 69, n. 2, p. 283-305, 2018. Acesso em: 13 fev. 2020.

CARVALHO, André Castro. Regime jurídico da e-cash bitcoin no direito financeiro brasileiro. Revista de Direito Público da Economia - RDPE -, Belo Horizonte, ano 16, n. 61, jan./mar. 2018. p. 5. Disponível em: http://www.bidforum.com.br/PDI0006.aspx?pdiCntd=250839. Acesso em: 13 fev. 2020.

CRYPTOUK. Code of conduct, de 14 de maio de 2019. Disponível em: https://cryptouk.io/codeofconduct/. Acesso em: 13 fev. 2020.

CVM. Comunicado Conjunto, de 13 de junho de 2019. Disponível em: http://www.cvm.gov.br/noticias/arquivos/2019/20190613-1.html. Comissão de Valores Mobiliários, 2019. Acesso em: 29 jan. 2020.

DALCASTEL, Marcia Bataglin. Criptomoeda ou criptoativo: em busca de uma regulação para o bitcoin. JOTA, 2018.2 Acesso https://www.jota.info/paywall?redirect_to=//www.jota.info/opiniao-eanalise/artigos/criptomoeda-ou-criptoativo-em-busca-de-uma-regulacao-para-o-bitcoin30042018. Disponível em: 13 fev.2020.

ENDO, Toshihide. 2a Sessão do Seminário de Tecnologia do G20, 2018. Disponível em: https://www.fsa.go.jp/common/conference/danwa/20190608/05.pdf. Acesso em: 30 jan. 2020. FOLEY, Sean; KARLSEN, Jonathan R.; PUTNIN̦Š, Tālis J. Sex, drugs, and bitcoin: How much illegal activity is financed through cryptocurrencies?. The Review of Financial Studies, v. 32, n. 5, p. 1798-1853, 2019. Disponível em: https://academic.oup.com/rfs/articleabstract/32/5/1798/5427781. Acesso em: 13 jan. 2020.

GRUPO DE AÇÃO FINANCEIRA INTERNACIONAL (GAFI). Guidance for a Risk-Based Approach to Virtual Assets and Virtual Asset Service Providers. jun. 2019. Disponível em: https://www.fatf-gafi.org/publications/fatfrecommendations/documents/guidance-rba-virtualassets.html. Acesso em: 29 jan. 2020. 
HOUBEN, Robby; SNYERS, Alexander. Cryptocurrencies and blockchain - legal context and implications for financial crime, money laundering and tax evasion. European Union: Policy Department for Economic, Scientific and Quality of Life Policies, jul. 2018. p. 76-79. Disponível em: http://www.europarl.europa.eu/cmsdata/150761/TAX3\%20Study\%20on\%20cryptocurrencies \%20and\%20blockchain.pdf. Acesso em: 2 dez. 2019.

HOUBEN, Robby; SNYERS, Alexander. Cryptocurrencies and blockchain - legal context and implications for financial crime, money laundering and tax evasion. European Union: Policy Department for Economic, Scientific and Quality of Life Policies, jul. 2018. p. 76-79. Disponível em http://www.europarl.europa.eu/cmsdata/150761/TAX3\%20Study\%20on\%20cryptocurrencies $\% 20$ and\%20blockchain.pdf

IANSITI, Marco; LAKHANI, Karim R. The truth about blockchain. Harvard Business Review, 2017. Disponível em: https://hbr.org/2017/01/the-truth-about-blockchain. Acesso em: 8 dez. 2019.

NAKAMOTO, Satoshi. Bitcoin: A peer-to-peer electronic cash system. Manubot, 2019. Disponível em: https://git.dhimmel.com/bitcoin-whitepaper. Acesso em: 8/12/19.

RIBEIRO, Aureo L. M. Projeto de Lei $n^{\circ}$ 2.303/2015, que altera as Leis $n^{\circ} 12.865$, de 2013 e 9.613, de 1988. Dispõe sobre a inclusão das moedas virtuais e programas de milhagem aéreas na definição de "arranjos de pagamento" sob a supervisão do Banco Central. Senado Federal, 2015. Disponível em: https://www.camara.leg.br/proposicoesWeb/fichadetramitacao?idProposicao=1555470. Acesso em: 29 jan. 2020.

RIBEIRO, Débora Elisa Lima. A (r)evolução das obrigações empresariais: do escambo ao bitcoin e o anseio por uma regulamentação brasileira. VIII Congresso Anual da AMDE. Revista da AMDE. Disponível em: http://www.revista.amde.org.br/index.php/ramde/article/view/261. Acesso em 28 jan. 2020.

RODRIGUES, G., KURTZ, L., OLIVEIRA, A., DUARTE, F., FALBO, L., \& dos Anjos, L. C. Criptomoedas e regulação antilavagem de dinheiro no G20. Instituto de Referência em Internet e Sociedade, 2019. Disponível em: http://irisbh.com.br/wpcontent/uploads/2019/09/criptomoedas_e_regulacao_antilavagem_de_dinheiro_no_G20_IRIS _0.pdf. Acesso em 28 jan. 2020. 
ULRICH, Fernando. A Moeda na Era Digital. Instituto Ludwig Von Mises Brasil, 2014. Disponível em: http://www.mises.org.br/Ebook.aspx?id=99. Acesso em: 8 dez. 2019.

URANAKA, Taiga. Japan grants cryptocurrency industry self-regulatory status. Reuters, 2018. Disponível em: https://www.reuters.com/article/us-japan-cryptocurrency/japan-grantscryptocurrency-industry-self-regulatory-status-idUSKCN1MY10W. Acesso em: 28 jan. 2020. 